\title{
Economia Política da Desgovernança Global ${ }^{\star}$
}

\author{
- Luiz Carlos Bresser-Pereira*
}

\begin{abstract}
RESUMO
A desgovernança econômica global, mais do que a governança, é uma das características mais marcantes, hoje, da economia mundial. Dois fatos confirmam esta afirmativa: as recorrentes crises do balanço de pagamentos em países em desenvolvimento, e o enorme déficit em conta corrente dos Estados Unidos. As crises em mercados emergentes são, essencialmente, o resultado de uma estratégia que o Norte propôs para o Sul: o crescimento com poupança externa. Dado o fato de que os fluxos de capital externo valorizam a taxa de câmbio, e que os países não aproveitaram as oportunidades de investimento nos anos 1990, tal estratégia não gerou aumento da acumulação de capital e crescimento, mas um grande déficit em conta corrente e crises (financeiras) de balanço de pagamentos. Por outro lado, o déficit em conta corrente dos Estados Unidos é um problema sério. Os Estados Unidos já são um país devedor, mas os ajustes continuam a ser adiados. Assim, a probabilidade de um soft landing é pequena. As duas fontes geradoras de instabilidade estão relacionadas com os déficits de conta corrente e a moeda sobrevalorizada. A política por trás disso tudo tem um nome: populismo cambial, uma das duas formas de populismo econômico (a outra é o populismo fiscal). Isto não é surpreendente em países em desenvolvimento, mas pode ser em um país desenvolvido como os Estados Unidos. Mesmo assim, quando considerados o retrocesso político e social que a sociedade americana vem experimentando desde o fim da Segunda Guerra Mundial, este fato deixa de ser surpreendente.
\end{abstract}

\section{PalaVRAS-CHAVE}

governança, déficit em conta corrente, taxa de câmbio, populismo

\section{ABSTRACT}

Global economic disgovernance rather than governance characterizes today the world economy. Two facts substantiate this assessment: the recurring balance of payment crises in developing countries, and the present enormous current account deficit in the United States. The emergent markets' crises are essentially the outcome of a strategy that the North proposed to the South: the growth cum foreign savings strategy. Given the fact that the inflow of capitals evaluate the exchange rate, and that the countries did not face major investment opportunities in the 1990s, such strategy led not to increase in capital accumulation and growth but to large current account deficits and to balance of payment (financial) crises. On the other hand, the US current account deficit is a serious problem. The US is already a debtor country, but adjustment continues to be postponed. Thus, the probability of a soft landing is small. Both sources of instability are related with current account deficits and overvalued currencies. The political economy behind has a name: exchange rate populism, one of the two forms of economic populism (the other is fiscal populism). This is not surprising in developing countries, but could be in a developed country like the United States. Yet, when one considers the political and social retrocession that the American society is experiencing since the end of World War II, it is not.

\section{KEY WORDS}

governance, current account deficit, exchange rate, populism

\author{
JEL Classification \\ EOO, FOO, FOI, F02, PI6
}

- Trabalho apresentado à conferência "A Economia Política da Governança”, Centre d'Etudes Monétaires et Financières - LATEC (Umr Cnrs), Dijon, 2-3 de dezembro de 2005.

* Professor Emérito da Fundação Getúlio Vargas. E-mail: lcbresser@uol.com.br; site: www.bresserpereira.org. br. End. para contato: Rua Araripina 106 - Cidade Jardim - CEP: 05603-030 - São Paulo - SP. Fone (II) 3816-6053 - Fax (II) 3816-5978.

(Recebido em fevereiro de 2006. Aceito para publicação em dezembro de 2006). 


\section{INTRODUÇÃO}

Governança global é uma expressão que se tornou popular nos anos 1990 para expressar a idéia de que, no cenário mundial, os Estados nacionais perderam autonomia e relevância tendo em vista que um sem-número de outros jogadores - instituições multilaterais, organizações da sociedade civil, movimentos sociais globais, empresas multinacionais - têm um papel cada vez maior a desempenhar. James N. Roseneau $(1990,1997)$ foi provavelmente o primeiro teórico a discutir amplamente, e em nível acadêmico sofisticado, o tema que atualmente já acumula uma vasta bibliografia. A idéia geral era de que a globalização estava fazendo com que os Estados-nação perdessem importância, enquanto um grande número de outros atores globais, começando com as instituições financeiras internacionais, passando pelas organizações sem fins lucrativos que constituem uma sociedade civil global, e terminando com as empresas multinacionais, estavam criando uma rede que efetivamente governava o mundo. Em outras palavras, o mundo estava mudando de internacional para global. Não vou discutir aqui essa idéia, que entendo ser parcialmente baseada na realidade e fortemente carregada de ideologia. Não há dúvida de que desde a Segunda Guerra Mundial a humanidade está gradualmente construindo um Sistema Político Internacional sob a proteção das Nações Unidas, que não deve ser confundido com esse conceito difuso de governança; também é verdade que está surgindo um certo tipo de sociedade civil global; mas a idéia de que os Estados-nação perderam relevância porque se tornaram mais interdependentes é antes uma maneira por meio da qual os países desenvolvidos tentam frear a competição oriunda dos países de renda média e mão-de-obra barata do que uma realidade. Na verdade, a maior interdependência entre os Estados-nação torna-os mais diretamente competitivos nas arenas globais e, portanto, mais estratégicos, não menos.

Por sua vez, a governança econômica global é a transposição do conceito para os problemas econômicos de nível mundial que os Estados-nação enfrentam atualmente. Como os atores principais são os Estados-nação, deveríamos falar em governança econômica internacional mais do que em governança econômica global. No entanto, independentemente da palavra utilizada - internacional ou global - o que vemos hoje em dia é que a governança econômica mundial é precária, apesar da tranquiilidade e prosperidade dos últimos cinco anos. É precária, em primeiro lugar, porque embora os Estados-nação estejam envolvidos em intensa competição internacional, os respectivos governos nacionais não são capazes de cooperar efetivamente e coordenar ações, evitando assim uma crise importante; em segundo lugar, porque uma crença fundamentalista em um mercado auto-regulador impede as ações necessárias; em terceiro lugar, porque as diferenças de poder e de níveis de desenvolvimento entre os Estados 
nacionais continuam sendo substanciais, abrindo espaço para padrões hegemônicos; ${ }^{1}$ em quarto lugar, porque as velhas e novas formas de populismo econômico - em particular o populismo cambial - assolam as políticas econômicas dos países pobres e dos países ricos. ${ }^{2}$ As duas primeiras causas tornam a governança econômica global ineficaz na medida em que ela é incapaz de coordenar açóes; a terceira acentua seu caráter injusto; e a última é fundamental para se compreender seu caráter instável, tendente a crises do balanço de pagamentos.

Neste trabalho, minha questão central é saber se a governança econômica internacional realmente se sustenta no mundo atual, ou se a desgovernança é uma palavra melhor para expressar a realidade presente. A governança global per se não existe, pois somente os Estados-nação e as organizações internacionais formais desempenham papéis relevantes. Mas será a governança econômica internacional um fato ou desgovernança é uma palavra que descreve melhor o que está ocorrendo? Estamos vendo políticas macroeconômicas coordenadas em todo o mundo ou pelo menos entre os países ricos, ou o que estamos vendo hoje em dia são profundos desequilíbrios, uma crise latente e um futuro incerto? Se é assim: por quê? Quais são as causas imediatas e, particularmente, quais as causas estruturais e institucionais por trás disso? Para responder a essas questôes, focalizarei minha atenção na taxa de câmbio e na conta corrente. Minha hipótese neste trabalho é que o mundo não conta realmente com uma governança econômica global. Temos, antes, uma desgovernança global, tendo em vista as crises recorrentes nos países em desenvolvimento e o enorme déficit em conta corrente nos Estados Unidos. Suas causas diretas são políticas macroeconômicas equivocadas por parte de todos os atores nacionais. Suas causas mais indiretas, porém, residem no populismo econômico ou, mais especificamente, no populismo cambial, e na recomendação que os países ricos vêm fazendo aos países de renda média de adotarem a estratégia do crescimento com poupança externa. O populismo econômico não é surpreendente nos países em desenvolvimento, nos quais as sociedades são mal organizadas e as elites são muitas vezes corruptas. É surpreendente, porém, no caso dos EUA. Vou sugerir, no entanto, algumas razóes pelas quais o populismo fiscal e cambial é hoje um verdadeiro problema para esse país. Na primeira parte, farei um breve levantamento das tentativas anteriores de criar uma governança econômica internacional; na segunda parte, discutirei as crises dos 'mercados emergentes' dos anos

1 Eu poderia dizer 'imperialistas', mas digo 'hegemônicos' apenas para diferenciar o imperialismo clássico, que envolveu colônias e pressões econômicas diretas, da moderna 'hegemonia' ou 'hegemonismo', que usa a hegemonia ideológica como principal instrumento de dominação. É interessante notar que a palavra é usada pelos norte-americanos, mas foi utilizada pela primeira vez por Gramsci para significar dominação ideológica interna.

2 Observem que estou falando de populismo 'econômico', não 'político'. O populismo econômico ocorre quando definha a organização do Estado ou o Estado-nação, para gastar mais do que arrecada, incorrendo, respectivamente, em déficits orçamentários crônicos ou em déficits em conta corrente; o populismo político é essencialmente a prática dos políticos carismáticos de falarem diretamente ao povo sem a intermediação de partidos políticos. 
1970 e particularmente dos anos 1990, e mostrarei sua relação com a estratégia de crescimento com poupança externa; na terceira, discutirei o desequilíbrio em conta corrente nos EUA e buscarei suas causas indiretas no populismo cambial e no retrocesso político e social que esse país vem sofrendo desde a Segunda Guerra Mundial, provavelmente como conseqüência do surgimento de um individualismo agressivo, que rejeita a noção de público e lhe tira o único critério moral e político adotado pelas modernas sociedades seculares.

\section{BREVE HISTÓRICO}

Em um passado relativamente recente, a economia mundial contou com um sistema de governança. Era claramente um sistema de governança internacional, não global. Foi criado em 1944, na Conferência de Bretton Woods. Seu objetivo conhecido era estabelecer um sistema de governança econômica baseado em taxas fixas de câmbio, no qual o FMI desempenharia o papel de principal controlador financeiro e banco de último recurso. Pode-se dizer que o sistema era frágil e incompleto: que sua principal deficiência era a predominância da abordagem norte-americana do problema sobre a proposta feita por Keynes. ${ }^{3} \mathrm{O}$ fato, porém, é que testemunhamos seu fim em 1971, quando o dólar flutuou. Desde então, país após país, com exceção de algumas economias asiáticas, todos liberalizaram em graus diferentes seus fluxos internacionais e se envolveram em algum tipo de flutuação da taxa de câmbio.

Com a flutuação das moedas nacionais e o grande aumento dos fluxos de capitais, a instituição central de Bretton Woods, o FMI, perdeu importância como emprestador de último recurso, e terminou sendo apenas um cão de guarda para as autoridades de Washington em relação aos países em desenvolvimento. Perdeu importância nos anos 1980 porque, além de suas reservas serem pequenas em comparação com as dívidas que certos países conseguiram fazer no mercado financeiro internacional, revelou-se incapaz de oferecer uma solução para a grande crise da dívida externa; nos anos 1990 porque adotou a política de crescimento com poupança externa, isto é, de crescimento com déficits em conta corrente, mostrou ser uma política cada vez mais equivocada em relação aos países em desenvolvimento. Essa estratégia apareceu pela primeira vez nos anos 1970, em resposta à possibilidade e necessidade de reciclar as grandes reservas internacionais acumuladas pelos países produtores de petróleo após o primeiro choque do petróleo em 1973. No final dessa década, um segundo choque do petróleo, somado à inflação nos EUA e a um enorme aumento das taxas internacionais de juros, levou um grande número de países em desenvolvimento - os que estavam fortemente

3 Keynes propôs o 'bancor' - uma moeda internacional que seria criada, mas a delegação americana chefiada por White preferiu naturalmente uma solução que na prática reservasse para o dólar o papel de moeda reserva internacional. Ver, entre outros, Moggridge (1976); Raffer e Singer (2001). 
endividados ${ }^{4}$ - à moratória branca ou default: uma moratória que não foi decidida por eles, mas pelos bancos credores que, um a um, suspenderam a rolagem das dívidas. Essa crise, além de envolver enormes custos para os países em desenvolvimento (eles estão até hoje pagando o preço dessa crise com taxas de crescimento reduzidas), representou uma ameaça aos grandes bancos internacionais e, portanto, um risco para as economias desenvolvidas. Em vista da ameaça, seus ministros da fazenda, liderados pelo Secretário do Tesouro norte-americano, e tendo como agentes o FMI e o Banco Mundial, demonstraram uma notável capacidade de coordenação. Eles deram total apoio a seus bancos e impuseram aos países altamente endividados não apenas os ajustes fiscais e cambiais necessários, mas também o pagamento de grande parte da dívida. O Plano Baker, de 1985, é geralmente apresentado como um exemplo dessa coordenação, mas ela começou antes, quando irrompeu a crise da dívida, e foi mais informal do que formal. A solução do problema, entretanto, só veio a partir de uma proposta do Brasil feita em setembro de 1987, que dezoito meses mais tarde transformou-se no Plano Brady. ${ }^{5}$

A coordenação formal da economia mundial foi inicialmente assumida pelo G-5 e mais tarde pelo G-7 - mecanismos institucionais informais que reuniam os ministros da fazenda dos países ricos. Eles obtiveram alguns êxitos na coordenação da economia mundial nos anos 1980, quando tiveram de enfrentar dois importantes problemas financeiros: a crise da dívida dos países em desenvolvimento e a sobrevalorização do dólar. Esses dois problemas eram novos: desde os anos 1930 a economia mundial não enfrentava desafios semelhantes. Este último problema foi enfrentado com sucesso em 1985, com o Acordo Plaza, e envolveu uma ação coordenada por parte dos maiores bancos centrais. ${ }^{6}$ Essa coordenação foi relativa, mas suficiente para provocar a desejada depreciação do dólar e a eliminação do déficit em conta corrente dos EUA. O grande vencedor com esse acordo foram os EUA, que equilibraram sua conta corrente, resgataram o dólar e garantiram a manutenção de seu papel como reserva de dinheiro do mundo, sem incorrer no aumento da inflação; o grande perdedor foi o Japão - o país que havia baseado seu crescimento em uma taxa de câmbio relativamente desvalorizada. ${ }^{7}$ É difícil, porém, negar o sucesso do Acordo Plaza do ponto de vista dos Estados Unidos. Não apenas porque o acordo conseguiu alcançar os objetivos estabelecidos, mas também por uma questão de correspondência: se se espera que os países façam política macroeconômica, não há razão para que o mundo também não a faça. No entanto, imediatamente após o acordo, foi apresentado o clássico argumento

4 Com exceção da Colômbia, que não estava endividada, mas teve suspensa a rolagem de seu crédito.

5 Para um relato da proposta do Brasil, ver "A turning point in the debt crisis" (Bresser-Pereira, 1999).

6 O Acordo Plaza foi assinado pelo G-5 em Nova York, no dia 22 de setembro de 1985, no Hotel Plaza.

7 Como conseqüência do acordo, o yen caiu de 240 para cerca de 150 dólares, provocando inicialmente depressão na economia japonesa; em seguida, uma euforia especulativa; e finalmente, a partir de 1990, em estagnação que durou quinze anos. Para uma análise do alto custo para o Japão da apreciação do yen provocada pelo Acordo Plaza, ver Kuroda (2004). 
de que a desvalorização do dólar aconteceria de qualquer modo: as forças de mercado corrigiriam a situação. (Feldstein, 1988, p. 1 e 5; Frenkel e Rocket, 1988). Feldstein manifestou forte oposição à administração da taxa de câmbio e mais amplamente à cooperação em política macroeconômica: "Acredito que a busca de metas cambiais possa ser ao mesmo tempo fútil e economicamente danosa.” Por quê? Os acordos não fariam sentido porque, dadas as dificuldades de reunir diferentes Estados-nação, "é provável que a tentativa de buscar coordenação em um amplo leque de politicas macroeconômicas resulte em desacordos e desapontamentos", e porque o dólar de qualquer modo continuaria a cair, "já que o futuro déficit comercial implicado pelo nivel do dólar seria grande demais para poder se financiar de outra maneira." Em outras palavras, o mercado resolveria tudo.

As óbvias dificuldades envolvidas na coordenação internacional, somadas a essas críticas, provavelmente explicam o fracasso da coordenação internacional da política macroeconômica nos anos 1990. Uma terceira explicação, porém, é menos conhecida: o suporte teórico dado aos grandes déficits em conta corrente nos países em desenvolvimento. Se o Tesouro norte-americano, por meio do FMI e do Banco Mundial, estava, desde o início dos anos 1990, aconselhando tais países a se envolverem em uma 'estratégia de crescimento com poupança externa' e a abrirem as contas de capital, não fazia muito sentido pensar em taxas de câmbio coordenadas: no mínimo a taxa de câmbio dos países em desenvolvimento que aceitassem essa estratégia ficaria necessariamente desequilibrada (uma taxa de câmbio equilibrada sendo aqui entendida como aquela que assegura intertemporalmente uma conta corrente em torno de zero): ela teria de ficar sobrevalorizada enquanto durasse a estratégia. ${ }^{8}$ Isto de fato aconteceu e, não surpreendentemente, essa década foi marcada por enormes crises financeiras. Nos anos 2000, outro grande desequilíbrio passou a ameaçar as finanças internacionais: o dólar, embora se depreciando em relação ao euro, mais uma vez se valorizou perigosamente, sobretudo em relação às moedas do Leste e Sudeste asiáticos, e o déficit norte-americano em conta corrente atinge novos recordes. Tendo em vista esses fatos, é compreensível que se possa duvidar da existência de uma governança econômica global. Em lugar disso, o que os fatos sugerem é uma 'desgovernança' econômica global, ou um grande desequilíbrio econômico global. Se é assim, quais são os dados que sustentam tal desequilíbrio? Quais são suas causas? E quais são as tendências a partir de agora?

8 Sei que o conceito de qual seria a taxa de câmbio de equilíbrio é um tema aberto a enorme debate acadêmico. Estou apenas propondo aqui um critério simples e pragmático para definir o que é uma 'taxa de câmbio equilibrada', assumindo que isto é menos exigente do que o conceito de 'taxa de câmbio de equilíbrio'. 


\section{AS CRISES DOS ANOS 1990 E A ESTRATÉGIA DE CRESCIMENTO COM POUPANÇA EXTERNA}

Começarei com as crises do balanço de pagamentos que atingiram as economias em desenvolvimento de renda média nos anos 1990 e no início dos anos 2000. Elas começaram com a crise do México em 1994; foram seguidas pela crise asiática de 1997, pela russa no início de 1998, pela brasileira no final de 1998, e finalmente pela crise da Argentina em 2002. Desse modo, essas economias, que tinham acabado de sofrer as grandes crises da dívida dos anos 1980, estavam novamente enfrentando problemas semelhantes. O fracasso do regime internacional estabelecido em 1971 e a incapacidade do FMI de enfrentá-lo tornaram-se evidentes. Mas, enquanto no caso do abandono das taxas fixas de Bretton Woods é possível alegar que era inevitável - que o regime cambial em um mundo tão integrado comercial e financeiramente não seria nem fixo, como gostariam os keynesianos, nem flutuante, como sonham os economistas neoclássicos, mas administrado, como efetivamente o é (Bresser-Pereira, 2004) - no caso do FMI o fracasso foi evidente: essa organização foi incapaz de resolver a crise da dívida externa dos anos 1980 e contribuiu ativamente para as crises de balanço de pagamentos dos anos 1990.

Embora elas fossem frouxamente chamadas de crises financeiras, eram especificamente crises do balanço de pagamentos, porque envolviam a suspensão da rolagem das dívidas pelos credores. ${ }^{9}$ Elas estavam diretamente relacionadas a um pesado endividamento externo e/ou a grandes déficits em conta corrente, a uma crescente perda de crédito e, como fator desencadeante, à suspensão pelos credores estrangeiros do refinanciamento de suas dívidas internacionais - públicas ou privadas. No entanto, como os países também enfrentavam déficits fiscais, o FMI e o Banco Mundial e mais amplamente a ortodoxia convencional atribuíram as crises do balanço de pagamentos ao desequilíbrio fiscal e não ao déficit em conta corrente. Esta era uma abordagem conveniente, porque reafirmava a crença de que todos os problemas se originavam no setor público, e se somava ao argumento dos déficits gêmeos que permitia que as autoridades internacionais e locais não se preocupassem com os crescentes déficits em conta corrente. Ao contrário, estavam despreocupadas, pois, desde o início dos anos 1990, enquanto o Plano Brady estava equacionando a crise da dívida, ocorria uma nova onda de empréstimos para os agora denominados 'mercados emergentes', e a ortodoxia convencional, ou seja, o conjunto de diagnósticos, recomendações e pressões que os países ricos fazem aos em desenvolvimento assumia uma nova tese - a da abertura da conta de capitais combinada com a estratégia de crescimento com poupança externa.

9 Crises financeiras no sentido estrito são crises dos mercados bancário e financeiro. As crises da dívida também são financeiras, mas prefiro chamá-las de crises do balanço de pagamentos para indicar sua natureza específica. 
TABELA I-CRISE ASIÁTICA: SALDOS EM CONTA CORRENTE 1995-1999 (\% DAS EXPORTAÇÕES)

\begin{tabular}{lccccc}
\hline & 1995 & 1996 & 1997 & 1998 & 1999 \\
\hline Indonésia & $-12,10$ & $-13,56$ & $-7,75$ & $+7,48$ & $+10,39$ \\
Coréia & $-5,89$ & $-15,12$ & $-5,09$ & $+25,60$ & $+14,25$ \\
Malásia & $-10,31$ & $-4,89$ & $-6,32$ & $+11,39$ & $+13,13$ \\
Filipinas & $-7,46$ & $-11,94$ & $-10,89$ & $+4,05$ & $+18,46$ \\
Tailândia & $-19,20$ & $-20,59$ & $-4,14$ & $+21,55$ & $+17,37$ \\
\hline
\end{tabular}

Fonte: Banco de Dados de Indicadores do Desenvolvimento Mundial.

Atribuir as crises de balanço de pagamentos ao déficit público em vez de ao déficit em conta corrente já não fazia sentido no caso dos países latino-americanos, mas como esses países sempre enfrentaram problemas fiscais, essa conclusão não era clara. No caso da crise asiática, porém, esse tipo de explicação logo revelou carecer de suporte empírico já que esses países mostravam contas fiscais razoavelmente equilibradas. Conforme podemos ver pela Tabela 1 , o verdadeiro desequilíbrio estava na conta corrente, que apresenta déficits elevados e crescentes até 1997. Como observou Joseph Stiglitz (2002: 99), "os paises do leste da Ásia não tinham necessidade de capital adicional, tendo em vista sua elevada taxa de poupança, mas ainda assim foi estimulada a liberalização da conta de capital nesses países no final dos anos 1980 e início dos anos 1990. Acredito que liberalização da conta de capital foi o fator isolado mais importante que levou à crise." A isto é necessário somar o fato de que os bancos financiaram os investimentos especulativos e irresponsáveis em imóveis - um aspecto especificamente financeiro das crises. Como no caso da crise da América Latina, o fator desencadeante foi a suspensão do crédito internacional, configurando assim uma típica crise do balanço de pagamentos. A Tabela 1 apresenta também os superávits em conta corrente logo após a crise - superávits que mostram que esses países aprenderam rapidamente a lição. Como afirma uma nota informativa preparada logo após a crise pela secretaria da UNCTAD (1998):

"Embora diferentes influências tenham estado em jogo em diferentes paises da região, uma caracteristica comum é que a crise tem sua origem no setor privado e assumiu a forma de um grande fracasso de mercado. Pode-se descrevê-la ou como uma excessiva tomada de empréstimos externos pelo setor privado, ou como uma excessiva concessão de empréstimos pelos mercados financeiros internacionais. Em todo caso, como ressaltado 


\section{por Alan Greenspan, Presidente do Federal Reserve dos EUA, é evidente que mais investimento foi canalizado para tais economias do que poderia ser lucrativamente empregado com risco moderado."}

Em todos os casos, as crises tiveram como pano de fundo a estratégia adotada pelo pensamento econômico convencional de crescimento com poupança externa, isto é, com déficits em conta corrente, que provocaram a sobrevalorização das moedas locais e evoluíram para crises do balanço de pagamentos. Se os déficits em conta corrente tivessem sido mantidos rigorosamente sob controle, evitando-se o aumento da relação dívida/exportações, as crises poderiam ter sido evitadas, mas a relativa valorização das moedas locais e a conseqüente substituição da poupança interna pela poupança externa ainda prevaleceriam, provocando ônus de longo prazo em termos de saídas de recursos sob a forma de juros e dividendos que não eram proporcionais ao investimento 'líquido’ originário da poupança externa.

Assim, o FMI desempenhou um papel ativo no estímulo ao endividamento externo omitindo-se de fazer a crítica aos déficits em conta corrente. Isto é particularmente verdade nos casos das crises mexicana de 1994, brasileira de 1998 e argentina de 2002. Contraditória e pateticamente, o FMI - que era bem conhecido por suas políticas 'ortodoxas', 'duras', exigentes (e geralmente criticado por essa razão) - mostrou uma surpreendente frouxidão no caso dos déficits em conta corrente: na verdade essa instituição apoiou o populismo cambial que as apreciações cambiais viabilizam ao haver endossado a estratégia de crescimento com poupança externa patrocinada pelo Tesouro dos Estados Unidos. ${ }^{10}$

Foi essa estratégia que, desde os anos 1970, substituiu a lei das vantagens comparativas na neutralização da capacidade de competição dos países em desenvolvimento. Nos anos 1970, com o aparecimento dos primeiros NICs (newly industrialized countries), o mundo rico compreendeu que sua estratégia antiprotecionista tinha se exaurido (agora eram eles que precisavam de proteção), e concluiu que a lei da vantagem comparativa tinha agora pouca utilidade para eles. Tendo em vista as novas condiçôes, e dado o fato de que a globalização implicou aumento da concorrência econômica entre todos os países, os países ricos gradualmente perceberam que a estratégia de crescimento com poupança externa, aliada à abertura das contas de capital e à proteção dos direitos de propriedade, poderia desempenhar o papel de frear a ameaça representada pelas economias em desenvolvimento de renda média. Déficits em conta corrente foram entendidos como inerentes à condição de países em desenvolvimento, e os países foram

10 Essa estratégia foi formulada de maneira mais precisa quando Laurence Summers foi Subsecretário do Tesouro, no governo Clinton. Tenho trabalhado na crítica a essa 'contra-estratégia' há vários anos (Bresser-Pereira e Nakano, 2003; Bresser-Pereira e Varela, 2004; Bresser-Pereira e Gala, 2005), porque rejeitá-la me parece hoje tão importante quanto foi necessário criticar a lei das vantagens comparativas para iniciar a industrialização. 
aconselhados a financiá-los com empréstimos externos ou com investimento externo direto. $\mathrm{O}$ crescimento se transformou em uma competição entre países em desenvolvimento para obter mais crédito e mais 'credibilidade' e, em conseqüência, mais poupança externa. Mas como os empréstimos ou investimentos externos implicavam uma apreciação da taxa de câmbio e o aumento do consumo, houve uma maciça substituição de poupança interna por poupança externa, e pouco ou nenhum crescimento das taxas de acumulação de capital e das taxas de crescimento do PIB. A dívida externa, porém, aumentou e acabou explicando as crises do balanço de pagamentos nos anos 1990. A condição para a 'credibilidade' das políticas econômicas dos países em desenvolvimento era a de que obedecessem os conselhos da ortodoxia convencional, mas, na medida em que obedeceram, acabaram perdendo o que realmente importa que é solvência e crédito.

Essa explicação para as crises dos anos 1890, baseada nos déficits em conta corrente e no elevado endividamento externo, contradiz a costumeira 'explicação baseada no déficit fiscal' e de seus derivativos. Alves Junior, Ferrari Filho e Paula (2004) listaram os modelos convencionais que explicam as crises cambiais ou do balanço de pagamentos, todos baseados em hipóteses de 'mercados eficientes' e em desequilíbrios no setor público. Os modelos de primeira geração explicam as crises diretamente com os déficits fiscais; os modelos de segunda geração adicionam os jogos em que as autoridades econômicas estão envolvidas quando enfrentam a crise e têm de decidir se manterão a taxa de câmbio fixa ou se a deixarão flutuar; os modelos de terceira geração incluem o argumento classicamente adotado pela teoria econômica keynesiana: o caráter não regulado e especulativo das instituições financeiras. A explicação baseada nos déficits em conta corrente para as crises dos anos 1990 também difere da explicação pós-keynesiana e da explicação da Escola da Regulação, que dão ênfase à incerteza e fragilidade dos mercados financeiros e rejeita a hipótese dos mercados eficientes. ${ }^{11}$ Essas duas escolas estão certas em rejeitar a hipótese dos mercados eficientes e em enfatizar o caráter especulativo dos mercados financeiros. São características bem conhecidas. No entanto, na maioria dos casos, a fragilidade financeira e a especulação não levarão a crises do balanço de pagamentos se o país tiver uma política eficaz de limitação dos déficits em conta corrente e do endividamento externo: não apenas endividamento público, mas também privado. Em outras palavras, se um país tiver fundamentos sólidos (particularmente uma dívida externa moderada, déficits em conta corrente pequenos ou negativos, uma dívida pública moderada e pequenos déficits orçamentários), é pouco provável que ocorra nele uma crise do balanço de pagamentos. Existem alguns casos famosos de países que tinham fundamentos sólidos e entraram em crise, mas são obviamente exceçôes. Geralmente as crises envolvem os fundamentos. Elas podem ter uma origem fiscal, mas desde os anos 1970 elas estão fortemente relacionadas aos dé-

11 Para uma exposição abrangente da visão pós-keynesiana, ver Davidson (2002); para a visão da Escola da Regulação, ver Aglietta (2002). 
ficits em conta corrente e ao endividamento externo - um endividamento externo perversamente estimulado pelas autoridades de Washington e pelos mercados financeiros de Nova Iorque. Apesar de a experiência histórica mostrar que os países desenvolvidos atuais utilizaram principalmente poupança interna, os países em desenvolvimento são encorajados a caminhar à beira do abismo do alto endividamento externo, que seria sua condição 'natural' já que necessitariam receber capitais para crescer, mas os sábios conselheiros não deixam de recomendar que eles tenham cuidado e não caiam. $\mathrm{O}$ pior, nesse jogo, é que não há vantagem em andar à beira do abismo. Mesmo se o país controlar seus déficits em conta corrente e seu endividamento total, e não for colhido por crises, o desempenho de seu crescimento ficará prejudicado pelo fato de que as entradas de capital apreciam a moeda nacional, provocam aumento dos salários reais e do consumo interno, e a substituição da poupança interna pela poupança externa. Como argumentou Kregel (1999), são as políticas econômicas recomendadas pelo Norte, particularmente a política de abertura da conta de capitais, que prejudicam os fundamentos macroeconômicos do país; é essa abertura, acrescento, somada à política de crescimento com poupança externa que aprecia o câmbio e promove a substituição da poupança interna pela externa. ${ }^{12}$

\section{A CONTA CORRENTE DOS EUA}

Após as crises de 1997 e 1998, o Tesouro norte-americano e o FMI provavelmente alteraram algumas de suas opinióes mais radicais sobre o tema, mas conservaram seus principais pressupostos e objetivos. Por outro lado, nenhuma solução institucional ou de governança foi apresentada a esse problema em nível internacional. Em seu relatório, a Comissão Meltzer (1999), que foi criada pelo Congresso dos EUA para estudar o problema, sugeriu que o FMI deveria agir como um emprestador de última instância. Os países que reunissem certas condições de solvência ex ante teriam direito a financiamento automático, não sendo exigidas condicionalidades ou negociações adicionais. Mas, como ressaltou o World Trade Report (p. 72) da UNCTAD, "sem liberdade para criar sua própria liquidez, o Fundo teria de contar com os grandes paises industrializados para garantir os fundos necessários a tais operações. Nessas circunstâncias é altamente questionável se ele realmente conseguiria agir como um emprestador imparcial de uiltima instância, semelhante a um Banco Central nacional, pois suas decisões e recursos dependeriam do consentimento de seus maiores acionistas, que são tipicamente credores." Isto foi tudo. A idéia de reestruturar a arquitetura da governança econômica global foi descartada.

12 Para a crítica formal da estratégia de crescimento com poupança externa, ver Bresser-Pereira e Gala (2005). 
Tal como os países asiáticos, os latino-americanos também aprenderam em parte a lição e, como podemos ver nas Tabelas 2 e 3 , deixaram de incorrer em enormes déficits em conta corrente. Todos os sinais, no entanto, são de que os EUA não aprenderam. Contraditoriamente, se não pateticamente, o país que de modo tão inflexível convenceu os países em desenvolvimento a se envolverem na estratégia de crescimento com poupança externa - uma estratégia que não levou em conta os interesses nacionais dos países receptores - acabou ele próprio sendo prisioneiro dessa proposta desastrosa. Enquanto os países asiáticos e latino-americanos estavam se recuperando de suas crises, os Estados Unidos foram colhidos por enormes déficits orçamentários e déficits em conta corrente extremamente elevados. Tais déficits são recordes absolutos, e estão transformando os Estados Unidos, o mais rico e poderoso Estado-nação do mundo, em uma 'nação devedora'. De acordo com William R. Cline, que escreveu um livro com esse título $(2005, \mathrm{p} .1)$, "O déficit [em conta corrente] é maior do que em qualquer outra época nos 135 anos para os quais se dispóe de dados." Os dados que ele apresenta mostram que após um período entre 1869 e 1914, que se caracterizou pelo fato de os déficits serem compensados por superávits, a economia dos Estados Unidos viveu um longo período de superávits em conta corrente, que continuou até o início dos anos 1980. A partir desse momento, temos uma primeira queda importante entre $1982 \mathrm{e}$ 1987, quando os déficits em conta corrente alcançaram 3,4\% do PIB, uma recuperação até 1992 e, desde então, um crescente déficit, que alcançou 6\% do PIB em 2004 e atualmente está por volta de 7\% do PIB. Como mostram as Tabelas 2 e 3, em 2004 o déficit em conta corrente, de US\$ 665,9 bilhões, representou 58\% das exportações.

TABELA 2 - SALDO EM CONTA CORRENTE 1999-2004 POR REGIÕES (BILHÕES DE DÓLARES DOS ESTADOS UNIDOS)

\begin{tabular}{lrrrrrr}
\hline & 1999 & 2000 & 2001 & 2002 & 2003 & 2004 \\
\hline EUA & $-296,8$ & $-413,4$ & $-385,7$ & $-473,9$ & $-530,7$ & $-665,9$ \\
União Européia $^{1}$ & $+21,0$ & $+5,3$ & $+18,9$ & $+62,7$ & $+97,5$ & $+88,5^{4}$ \\
América Latina $^{2}$ & $-57,0$ & $-58,4$ & $-53,4$ & $-21,1$ & $-3,5$ & $+4,2^{5}$ \\
Países Asiáticos Dinâmicos $^{3}$ & $+236,1$ & $+241,1$ & $+186,9$ & $+234,2$ & $+295,6$ & $+386,4^{4}$ \\
Exportadores de Petróleo $^{4}$ & $+15,9$ & $+66,7$ & $+45,8$ & $+48,2$ & $+77,2$ & $+118,6$ \\
Outros países & $+88,0$ & $+165,0$ & $+188,8$ & $+154,3$ & $+67,2$ & $+71,5$ \\
\hline
\end{tabular}

Fontes: Banco de Dados de Indicadores do Desenvolvimento Mundial e www.cepal.org. Observações: 1. A Europa dos 15 mais a Suíça. 2. Exclui a Venezuela; 3. Japão, China, India, Coréia, Indonésia, Tailândia, Malásia, Cingapura, Filipinas e Vietnã, e Rússia; 4. Venezuela, Noruega, Kuwait e Arábia Saudita; 5. Estimativas. 
TABELA 3 - SALDO EM CONTA CORRENTE 1999-2004 POR REGIÕES (\% DAS EXPORTAÇÕES)

\begin{tabular}{lcccccc}
\hline & 1999 & 2000 & 2001 & 2002 & 2003 & 2004 \\
\hline EUA & $-30,72$ & $-38,60$ & $-38,31$ & $-48,56$ & $-52,00$ & $-58,05$ \\
União Européia & $+0,72$ & $+0,18$ & $+0,63$ & $+1,97$ & $+2,58$ & $+2,08^{4}$ \\
América Latina & $-17,77$ & $-15,63$ & $-14,69$ & $-5,77$ & $-0,88$ & $+0,87^{4}$ \\
Países Asiáticos Dinâmicos & $+16,58$ & $+14,20$ & $+11,93$ & $+13,80$ & $+14,67$ & $+15,70^{4}$ \\
Exportadores de Petróleo & $+10,30$ & $+30,88$ & $+23,36$ & $+24,00$ & $+31,81$ & $+37,72$ \\
\hline
\end{tabular}

Fontes: Banco de Dados de Indicadores do Desenvolvimento Mundial e www.cepal.org.

Esse é, definitivamente, um problema grave. Alguns autores insistem em desconsiderar o problema, argumentando que apesar de ter se tornado um país devedor, a diferença entre os rendimentos obtidos pelos residentes dos EUA em seus investimentos no exterior e o rendimento médio dos investimentos externos nos Estados Unidos é grande. ${ }^{13}$ Este fato, somado aos efeitos da revalorização da depreciação de 2002-03, vem neutralizando os custos financeiros da posição internacional líquida negativa, mas não muda o quadro de forma essencial. Se compreendermos que no presente desequilíbrio da economia norte-americana há um aspecto de estoque e um aspecto de fluxo - a dívida externa e o déficit em conta corrente, respectivamente -, esse argumento referente ao maior retorno dos investimentos externos norte-americanos realmente reduz o peso da dívida líquida, mas não muda o fato de que a conta corrente está altamente deficitária. Há um outro argumento, que é compartilhado principalmente pelos governadores do Federal Reserve Bank, ${ }^{14}$ e que é mais explícito e mais arrogante em seu desprezo pelos déficits nas contas externas, o déficit não é culpa dos EUA, mas dos países que têm moedas depreciadas. Como relatou a revista The Economist (28 de abril de 2005), "ultimamente quase todos os governadores do Federal Reserve norte-americano fizeram discursos sobre o déficit em conta corrente do país, atualmente em $6,3 \%$ do PIB e subindo. Vários deles pareciam incrivelmente tranqüilos. Sim, dizem eles, o desequilibrio é grande, mas é não culpa dos EUA; muito provavelmente, ele será resolvido sem maiores problemas." Assim, o ajuste terá de ser feito pelos outros, não pelos EUA.

13 Ver, por exemplo, Hausmann e Sturzenegger (2005). De acordo com esses dois autores, em 2004 a renda externa líquida foi de US\$ 30 bilhões, um número similar ao de 1980, apesar do fato de, entre 1980 e 1994, os EUA terem acumulado um déficit em conta corrente de US\$ 4,500 bilhões. Deveríamos, no entanto, ter em mente que apesar desses US\$ 30 bilhões líquidos positivos o déficit em conta corrente dos EUA em 2004 foi de US\$ 665,9 bilhões, como podemos ver na Tabela 2.

14 Não por Greenspan, mas principalmente pelo novo presidente do Federal Reserve Bank, Ben S. Bernanke (2005). 


\section{TABELA 4 - EMISSÃO LÍQUIDA DE DÍVIDA NO MERCADO INTERNACIONAL}

\begin{tabular}{lcc}
\hline & 1998 & 2003 \\
\hline Dólar & 60,3 & 24,6 \\
Euro & 32,9 & 65,2 \\
Yen & $-3,9$ & $-1,3$ \\
Outras moedas & 10,8 & 11,4 \\
\hline
\end{tabular}

Fonte: BIS Quartely, vários números; compilação de Wong e Khan (2006).

Os Estados Unidos provavelmente continuarão sendo a grande potência econômica e política durante muitos anos, mas serão uma potência em declínio, na medida em que o dólar tenderá, cada vez mais, a perder sua posição como reserva internacional: a participação do dólar nas reservas internacionais, que era de $80 \%$ em meados dos anos 1970, está hoje em torno de 65\%. (The Economist, 2004). Por outro lado, o euro tem-se apreciado em relação ao dólar, e, como podemos ver na Tabela 4, nos últimos anos as emissões de novas dívidas internacionais passaram a ser feitas não mais principalmente em dólares mas em euros. Como escreveu James Galbraith (2004), "durante décadas, o mundo ocidental tolerou o 'privilégio exorbitante' de uma economia com reservas em dólares porque os Estados Unidos eram a potência indispensável, que fornecia segurança confiável contra o comunismo e a insurreição, sem violência ou opressão intoleráveis, portanto condições sob as quais muitos paises neste lado da Cortina de Ferro cresceram e prosperaram. Essas justificativas se evaporaram 15 anos atrás, e a 'Guerra Global contra o Terror' não é uma substituição convincente. Assim, o que era antes um acordo relutante com a potência hegemônica que estabilizava o mundo é agora amplamente visto como um subsidio remanescente em favor de um Estado predador." A hipótese de que o resto do mundo, sobretudo os dinâmicos países asiáticos, continuará a financiar os Estados Unidos indefinidamente, e de que o que temos agora é apenas um 'novo Bretton Woods' (Dooley, Folkerts-Landau e Garber, 2003) simplesmente não é realista. Esses países estarão interessados em financiar os Estados Unidos e em aumentar as reservas à medida que essa estratégia frear a valorização de suas moedas e manter em rápido crescimento suas economias impulsionadas pela exportação. ${ }^{15}$ Mas há limites para essa estratégia - limites por parte desses países, que estão vendo a fragilidade da economia norteamericana, e limites por parte dos Estados Unidos. Eles estão vendo que a situação da dívida do país está se deteriorando, e que nenhuma medida está sendo tomada para corrigir essa tendência. Como observa Jarret $(2005$, p. 14), "projeções preliminares do

15 Mais recentemente, esses três autores (Dooley, Folkerts-Landau e Garber, 2005) vieram com a alegação de que, contrariamente à 'análise convencional', o déficit em conta corrente dos EUA também não é motivo de preocupação, porque o euro deve se valorizar em relação ao dólar e, em um segundo momento, o euro e o dólar irão se valorizar com relação ao renmimbi, mas isto são apenas previsões. No final, isto vai acontecer, mas provavelmente de maneira problemática, não da maneira suave que os autores supõem. 
que poderia acontecer às contas externas nos próximos anos, na ausência de qualquer mudança no dólar, variam significativamente, mas mostram uma rápida ampliação do déficit." Assim, está ficando cada vez mais evidente que os 'custos de transição' totais em adiar o ajuste estão crescendo regularmente. Se a decisão de fazer o ajuste for tomada em uma fase inicial, os custos líquidos da transição provavelmente serão altos, mas, em compensação, a economia voltará mais cedo à estabilidade e ao crescimento: os custos totais de transição serão menores. Tentar adiar indefinidamente o ajuste normalmente acabará em uma grave crise, que imporá o ajuste. ${ }^{16}$

\section{AS CAUSAS ESTRUTURAIS E DE ECONOMIA POLÍTICA SUBJACENTES}

Não discutirei as perspectivas desse grande déficit em conta corrente. A literatura sobre o tema já é exaustiva, com os autores se dividindo entre pessimistas, que acreditam em um 'pouso forçado', e otimistas, prevendo um 'pouso suave'. Sobre este assunto, deve-se apenas lembrar que há uma importante diferença entre o desequilíbrio de 1985 e o desequilíbrio atual. Naquela época, a supremacia do dólar não estava sendo questionada, hoje sim. Além disso, naquela época os Estados Unidos eram um credor líquido internacional, hoje são um devedor líquido: de uma posição líquida positiva de US\$ 298 bilhões em 1983, foram para uma posição líquida negativa de US\$ 2430 bilhões em 2003. (Nonnenberg, 2005). Também não discutirei as soluções para as crises. Embora o governo dos Estados Unidos (Congresso e Tesouro) insista em atribuir o problema a uma moeda chinesa 'artificialmente depreciada', o fato é que o superávit chinês explica apenas uma pequena parte do déficit dos Estados Unidos. Na verdade, o ajuste macroeconômico norte-americano necessário envolverá um ajuste fiscal e uma desvalorização do dólar. Provavelmente apenas o ajuste fiscal não será suficiente: quando o governo Clinton atingiu o equilíbrio na conta fiscal, a conta corrente ainda estava mostrando um déficit.

O que farei é pesquisar a economia política subjacente. Com relação aos Estados Unidos, as causas diretas do déficit em conta corrente estão relacionadas à solução do desperdício fiscal e do dólar sobrevalorizado. Com relação ao resto do mundo, a explicação está em parte na moeda chinesa relativamente depreciada, e nas moedas ainda mais depreciadas dos outros países asiáticos dinâmicos (uma vez que a China tem um grande superávit comercial com os Estados Unidos, mas um déficit com seus vizinhos), mas um novo e importante fator que explica o aumento do déficit em conta corrente a partir de 2005 é o aumento acentuado dos preços do petróleo. De acordo com estimativas do FMI, em 2005 o superávit em conta corrente dos países produtores de petróleo ficou em torno de US $\$ 400$ bilhões, contra US\$ 200 bilhôes

16 Sobre o conceito de custos de transição líquidos e totais, ver Bresser-Pereira e Abud (1997). 
dois anos atrás. ${ }^{17}$ Somente a Arábia Saudita deverá ter um superávit médio de US\$ 100 bilhôes, que corresponde a $32 \%$ de seu PIB, contra o superávit da China, que será de apenas $6 \%$ do PIB. ${ }^{18}$

Quando examinamos o problema da governança global sob o ponto de vista da economia política, o que importa é compreender as causas políticas que estão por trás das causas diretas. A questão central é por que os Estados Unidos, que estão enfrentando há muitos anos moedas asiáticas relativamente desvalorizadas, e que estão agora enfrentando um novo choque do petróleo, não foram capazes de agir a tempo de evitar o agravamento do desequilíbrio das suas contas externas? Minha hipótese é de que há duas causas internas ao país que, combinadas, tornam-se particularmente poderosas. A primeira é antes estrutural do que uma causa de economia política. Numa referência à 'maldição dos recursos naturais', que assola em especial os países produtores de petróleo, chamarei essa causa de 'a maldição de ter uma moeda como reserva internacional'. Geralmente isto é visto não como uma maldição, mas como uma bênção. Um país que possui uma moeda tão valiosa é capaz, em primeiro lugar, de levantar empréstimos em sua própria moeda; em segundo lugar, pode levantar empréstimos a um custo muito baixo. Isto certamente é verdade, mas, em compensação, o incentivo a consumir demais, a poupar muito pouco e a levantar empréstimos de maneira irresponsável é forte. Não apenas porque os gastos envolvidos na tomada de empréstimos externos são pequenos, mas também porque o prestígio da moeda nacional a empurrará para cima, fará com que ela se valorize. Se as autoridades econômicas não estiverem vigilantes, promovendo ativamente o investimento em lugar do consumo e administrando ativamente a moeda nacional, a tendência será no sentido de um crescente endividamento externo. Tendo em vista, porém, o fundamentalismo de mercado que domina os governos dos Estados Unidos desde os anos 1980, essa vigilância e essa administração são improváveis.

Aliada a essa causa estrutural há uma causa estritamente de economia política: o 'populismo cambial'. Nos países em desenvolvimento esta é uma prática bem conhecida, que foi detectada pela primeira vez por um eminente economista argentino, Adolfo Canitrot (1975). ${ }^{19}$ O populismo cambial pode ser definido como a política de apreciar ou deixar que se aprecie o câmbio para reduzir a inflação e aumentar os rendimentos reais para obter apoio da sociedade. Trata-se de uma política freqüentemente adotada por governantes dos países em desenvolvimento: pode ela ser também praticada por um país rico como os Estados Unidos - um país que, por meio do FMI, tem consistentemente criticado o populismo fiscal? Minha resposta é sim, por duas razões.

17 A diferença entre esse número e o número correspondente em 2004 na Tabela 3 é conseqüência de um menor número de países produtores de petróleo nessa tabela.

18 The Economist, 12 de novembro de 2005: "Recycling the Petrodollars": p. 75-77.

19 Além de Canitrot, os trabalhos clássicos sobre o assunto são os de O’Donnell (1978), Diaz-Alejandro (1981) e Sachs (1989). Todos estes trabalhos foram republicados em Bresser-Pereira, ed. (1991). 
Primeiro, porque o populismo fiscal é um fenômeno bem discutido, mas o populismo cambial, não. Embora o conceito de populismo cambial já esteja presente no trabalho clássico de Canitrot, a expressão 'populismo cambial' é nova: foi provavelmente utilizada pela primeira vez em 2002. (Bresser-Pereira, 2002). Se populismo fiscal é o fato de o aparelho do Estado gastar mais do que arrecada, populismo cambial é o fato de o país gastar mais do que arrecada. Em segundo lugar, porque os norte-americanos resistem à idéia de que o populismo econômico possa ser aplicado a seu governo. No entanto, desde o fim da Segunda Guerra Mundial, os Estados Unidos vêm sofrendo um preocupante retrocesso político que os torna sujeitos a ambos os tipos de populismo. Com relação ao populismo cambial, a evidência objetiva é de que os grandes déficits em conta corrente dos anos 1980 e 2000 estavam associados a dois governos populistas: os governos Reagan e George W. Bush. Esses governos, porém, não foram fruto do acaso. Enquanto os Estados Unidos continuam a crescer em termos econômicos e técnicos, o corte de gastos políticos e sociais vai se tornando cada vez mais evidente. O aumento da concentração de renda é o produto combinado da tecnologia da revolução da informação, que reduziu a demanda por mão-de-obra não-qualificada, ao mesmo tempo que aumentou a demanda por mão-de-obra qualificada e gerencial, das importaçôes de produtos manufaturados de países em desenvolvimento com mãode-obra barata, e da imigração oriunda do Sul. ${ }^{20} \mathrm{~A}$ existência de um grande número de cidadãos excluídos dos benefícios do crescimento econômico lembra países em desenvolvimento como o Brasil. Por esta razão, a expressão pejorativa 'brasilianização’ é cada vez mais aplicada aos Estados Unidos. Também é aplicada à Europa, mas a situação lá é menos preocupante: a renda é substancialmente menos concentrada, os direitos sociais são mais universalmente garantidos e as eleiçôes dependem menos de dinheiro.

O fato é que após a Segunda Guerra Mundial os Estados Unidos eram o exemplo de democracia para o mundo, e o Presidente Roosevelt, com o New Deal, tinha colocado os Estados Unidos à frente de todos os outros países na proteção dos pobres. Hoje, isto acabou. Por quê? Responder a essa questão é ainda mais difícil, mas provavelmente uma grande parte está relacionada ao agressivo individualismo que tomou conta da sociedade norte-americana desde a guerra. Durante algum tempo, nos anos 1960, não apenas os valores utópicos mas principalmente os valores republicanos que estavam por trás dos Patriarcas Fundadores da república norte-americana pareciam se manter. Mas já naquela época uma onda ideológica individualista e neoliberal (ou ultraliberal, o oposto do que os norte-americanos chamam de 'liberal') estava tomando conta

20 Um recente estudo feito pelo Setor de Orçamento do Congresso norte-americano mostra que, nos EUA, a renda dos imigrantes latino-americanos que trabalham na construção civil, na indústria têxtil, em operações de manutenção, fornecimento de refeições e restaurantes é $50 \%$ menor do que a que é paga a norte-americanos pelos mesmos trabalhos. Somente na última década, o número de trabalhadores imigrantes aumentou de 13 para 21 milhões. Tal crescimento representou metade do crescimento da força de trabalho nesse período. (Valor [Financial Times] 15 de novembro de 2005). 
dos corações e mentes. Economistas e filósofos sofisticados como Buchanan, Olson, Friedman, Nozick, que propunham a 'escolha pública', a 'impossibilidade da ação coletiva em grandes organizações', a 'liberdade de escolha' ou o 'Estado mínimo' não estavam apenas defendendo o fundamentalismo de mercado, mas pregando o individualismo radical e negando a existência e a relevância do interesse público como uma motivação eficaz para a ação pública. Isto era uma coisa séria. Quando eles rejeitavam o interesse público, estavam automaticamente rejeitando a política democrática, que só pode sobreviver quando os políticos e os funcionários públicos têm como uma de suas forças motivadoras a luta pelo interesse público. Somente baseados em considerações do interesse público é que os políticos foram capazes de conduzir o contrato social liberal do século XIX, que limitou os abusos do Estado autoritário, e o contrato democrático do século XX, que estabeleceu alguns limites ao capitalismo dos robber barons. As consequiências morais dessa negação sobre as sociedades capitalistas seculares como as nossas são catastróficas. Nas sociedades religiosas do passado, a salvação e a revelação ofereciam critérios morais aos indivíduos. Nas modernas sociedades seculares, porém, quando o interesse público ou o bem comum são descartados da vida política, os cidadãos imediatamente deixam de ter um critério público e moral para seguir. As únicas coisas que são valorizadas são os interesses privados, e a única regra a ser seguida é a do mercado: competir, buscando ao mesmo tempo vantagens monopolistas. Neste quadro, a vida pública e social fica reduzida ao mercado. As forças brutas do capitalismo - injustiça, cobiça, corrupção e desprezo pelo meio ambiente natural - tomam conta de tudo. Este perigo estava presente desde que o capitalismo se tornou dominante na Inglaterra, e desde então homens e mulheres estão tentando mantê-lo sob controle usando como ferramenta o conceito republicano de interesse público. No século XVII, no âmbito do Estado absoluto, estava surgindo uma nova e nobre atividade, a política - política republicana e democrática - cujo papel seria o de limitar os excessos tanto do Estado absoluto como do mercado ganancioso. A história política do Estado liberal do século XIX e do Estado democrático do século XX é a história do esforço dos indivíduos republicanos, lutando para frear o absolutismo do Estado e os excessos do mercado. Na segunda parte do século XX, porém, essa convicção republicana tornou-se cada vez mais fraca nos Estados Unidos, o que abriu caminho para todos os tipos de comportamentos e teorias individualistas, quando não cínicos. As conseqüências desorganizadoras e desmoralizantes desse tipo de individualismo são poderosas e provavelmente ajudam a explicar o retrocesso político e social nos Estados Unidos e o fato de os governos estarem novamente recorrendo a práticas populistas sem serem punidos nas eleições. 


\section{A LÓGICA POR TRÁS DA GLOBALIZAÇÃO}

Em síntese, o enorme déficit em conta corrente dos Estados Unidos e os déficits em conta corrente dos países em desenvolvimento de renda média nos anos 1970 e novamente nos anos 1990 têm como pano de fundo o populismo cambial. Mas, em tempos de globalização, estes últimos respondem também a uma estratégia de dominação: a estratégia de crescimento com poupança externa. Enquanto, dentro dos Estados Unidos, o populismo econômico é apenas uma demanda da sociedade, suprida por políticos movidos por interesse próprio, no caso dos déficits em conta corrente e das crises do balanço de pagamentos dos países em desenvolvimento, além de políticos locais populistas e movidos por interesse próprio, temos uma outra causa: um poder hegemônico dando conselhos, fazendo recomendações e impondo condicionalidades por meio de instituições financeiras internacionais. ${ }^{21}$ No entanto, essa estratégia imperial envolvia um efeito bumerangue não previsto. Desde os acordos de Bretton Woods os Estados Unidos acreditavam que poderiam exercer quase sozinhos a liderança do sistema financeiro internacional. Depois que o dólar flutuou e os acordos foram enterrados, os Estados Unidos continuaram a acreditar que seriam capazes de manter intocado seu controle do sistema. $\mathrm{O}$ mercado - o suposto mercado auto-regulador - facilitaria o trabalho. Assim, os Estados Unidos sempre rejeitaram qualquer tentativa de criar um sistema financeiro internacional mais organizado e estruturado, em que seria possível exercer uma vigilância sobre as taxas de câmbio. Em vez disso, seus diferentes governos preferiram, em primeiro lugar, imaginar que os próprios Estados Unidos, com suas sólidas políticas macroeconômicas, seriam uma fonte de racionalidade; em segundo lugar, que eles contariam com o apoio dos outros países desenvolvidos, cujos problemas eram semelhantes aos que eles enfrentam; em terceiro lugar, que o FMI e o Banco Mundial, com seus mandatos atuais, e devidamente controlados pelo Tesouro norte-americano, seriam suficientes para manter todo o sistema sob controle - particularmente as economias em desenvolvimento populistas. Mas o problema que os Estados Unidos e os outros países ricos enfrentaram em relação a essas economias não foi unicamente seu 'populismo' ou seu 'nacionalismo': foi também a ameaça econômica que elas representaram a partir do momento em que começaram a exportar produtos manufaturados. Para neutralizar tal ameaça eles propuseram que esses países adotassem a estratégia de crescimento com poupança externa e a abertura das contas de capital, e que aceitassem a globalização não como um fato, mas como

21 Os norte-americanos preferem chamar seu país de 'potência hegemônica benevolente', mas sabemos bem que todos os países que atingem uma predominância econômica e militar tendem a agir de modo imperial em relação a outros, isto é, tendem a proteger seus interesses à custa dos interesses dos outros, usando seu maior poder. As formas sob as quais esse poder é exercido variam. No passado, o uso da força e da exploração direta era a norma; nos dias atuais ela é essencialmente ideológica, e se transmite por meio de recomendações e pressões para que os países mais fracos adotem políticas que não levam em conta seus interesses nacionais. 
uma ideologia - a ideologia de que os Estados-nação tinham se tornado irrelevantes na 'sociedade sem fronteiras'.

Essa estratégia, no entanto, teve uma primeira consequiência desastrosa para os países em desenvolvimento, enquanto representava uma ameaça para os ricos. A crise da dívida externa de 1980 obrigou os Estados Unidos a organizarem um quase-cartel de credores para defender seus bancos comerciais. Nos anos 1990, quando a estratégia de crescimento com poupança externa se repetiu, a primeira grande crise (a crise mexicana de 1994) representou uma ameaça à economia norte-americana e obrigou o governo dos Estados Unidos a intervir com enormes somas de que o FMI não dispunha. Como observa Paul Davidson (2002, p. 200), "a crise mexicana extravasou para o problema do dólar... dólar foi inicialmente arrastado para baixo pelo peso." As outras crises também foram desastrosas para os países em desenvolvimento que as sofreram, e ameaçadoras para os ricos. A presente crise ou ameaça de crise representada pelo déficit em conta corrente e pela crescente dívida externa norte-americanos é uma conseqüência do populismo cambial, aliada à arrogante convicção de que os Estados Unidos se tornaram tão poderosos depois do colapso do comunismo que poderiam se permitir tudo.

O que realmente temos por trás da desgovernança econômica global vigente é uma combinação de políticas cambiais frouxas, populismo econômico e uma estratégia equivocada em relação aos países em desenvolvimento de renda média. Esta combinação apresenta seis problemas principais. Primeiro, as crises provocadas pela estratégia de crescimento com poupança externa, nos países que a adotaram obedientemente, foram maiores do que se esperava: a idéia era limitar suas exportações e aumentar a renda em dólar dos lucros realizados pelas empresas multinacionais naqueles países, não causar crises. Em segundo lugar, os países asiáticos dinâmicos não acreditaram nessa estratégia e aproveitaram a oportunidade para conceber uma estratégia contrária de crescimento com poupança externa negativa. Desse modo, eles conseguiram manter suas taxas de câmbio relativamente depreciadas, e continuaram com suas estratégias impulsionadas pela exportação, mesmo se os ganhos de produtividade não as legitimassem. Em terceiro lugar, o superávit em conta corrente alcançado pelos países asiáticos tornou viável a manutenção de altos níveis de consumo interno e crescentes déficits correntes nos Estados Unidos. Em quarto lugar, o acentuado aumento dos preços do petróleo em 2005 e os enormes superávits comerciais experimentados pelos países produtores de petróleo estão acentuando os desequilíbrios em conta corrente. Em quinto lugar, a hipótese da eficiência do mercado, a idéia de que os mercados se auto-regulam, está se mostrando uma vez mais apenas ideológica. Em sexto lugar, a prática não corroborou a pretensa racionalidade por parte das políticas macroeconômicas adotadas pelo Tesouro norte-americano e pelo Federal Reserve. O Sr. Greenspan terminou seus dezoito anos como presidente do Federal Reserve Bank amplamente acla- 
mado pela competência e flexibilidade que empregou na administração da instituição - e subscrevo esse prêmio, particularmente em relação a sua administração da taxa de juros - mas estava acima de seus poderes evitar os erros de política que levaram à perigosa situação em que as economias norte-americana e mundial estão hoje em dia.

Propostas? Compartilho com muitos a crença de que é necessária uma melhor arquitetura do sistema financeiro internacional. Os Estados Unidos precisam recuperar o controle sobre seu déficit orçamentário e desvalorizar o dólar. O FMI precisa deixar de ser governado por acionistas e começar a ser uma verdadeira organização multilateral, e precisa ter os recursos necessários para agir como um verdadeiro emprestador de último recurso. As taxas de câmbio e os déficits em conta corrente precisam ser acompanhados mais de perto; seu equilíbrio deve ser visto não como dependente apenas das forças de mercado, mas de uma combinação dessas forças com uma administração macroeconômica competente. Os países em desenvolvimento precisam recuperar o controle sobre suas contas de capital, manter o controle de suas contas fiscais e limitar a tomada de empréstimos externos. Não há heterodoxia aqui. Heterodoxa ou pouco usual é o fato de eu atribuir as crises dos países em desenvolvimento à estratégia de crescimento com poupança externa, não a recomendação de prudência. Economistas competentes como John Williamson (2005) e Barry Eichengreen (2003), por exemplo, estão dizendo a mesma coisa. Enquanto as políticas mais gerais não são adotadas, no entanto, o que os países em desenvolvimento deveriam aprender é que o crescimento se faz essencialmente com recursos internos - que o capital se faz em casa, com poupança interna; que a poupança externa é desejável somente em ocasiões especiais, quando as oportunidades de investimento internas, expressas em altas taxas de lucro esperadas, entravam a tendência natural dos agentes econômicos de aumentar o consumo quando sua renda real é aumentada; que a razão alternativa para desejar a poupança externa - a escassez de poupança interna - é a típica idéia de senso comum que o raciocínio científico deve rejeitar. Acredito ser mais realista, no momento, denunciar o populismo cambial e a estratégia de crescimento com poupança externa do que colocar todas as nossas fichas na reforma da arquitetura financeira internacional. Mais cedo ou mais tarde essa reforma será feita, mas enquanto não o é, as autoridades econômicas em cada Estado-nação, desenvolvido ou em desenvolvimento, devem se lembrar de que a taxa de câmbio é o preço macroeconômico mais estratégico, e que a alternativa 'fixar ou flutuar' é falsa: a única política sensata é: 'administrá-la'. Afinal de contas, os países desenvolvidos fazem isso: por que não deveriam fazê-lo os países em desenvolvimento? 


\section{REFERENNCIAS}

Aglietta, Michel. Problèmes posés par la régulation monétaire. In: Jacquet, Pierre; Pisany-Ferry, Jean; Tubiana Laurence (eds.), Governance mondiale. Paris: La Documentation Française, 2002, p. 375-392.

Alves, Antonio J.; Ferrari Filho, Fernando; Paula, Luiz Fernando de. Crise cambial, instabilidade financeira e reforma do sistema monetário. In: Ferrari Filho, Fernando; Paula, Luiz Fernando de (orgs.), Globalização financeira. Petrópolis: Vozes, 2004, p. 369-461.

Bernanke, Ben S. The global saving glut and the US current account deficit. Richmond: Sandridge Lecture, Virginia Association of Economics, 10 March 2005.

Bresser-Pereira, Luiz Carlos A turning point in the debt crisis. Revista de Economia Política, v. 19, n. 2, p. 103-130, 1999.

Bresser-Pereira, Luiz Carlos. Financiamento para o subdesenvolvimento: o Brasil e o Segundo Consenso de Washington”. In: Castro, Ana Célia (org.), Desenvolvimento em debate: painéis do desenvolvimento brasileiro I, vol. 2. Rio de Janeiro: Mauad/BNDES, 2002, p. 359-398.

Bresser-Pereira, Luiz Carlos; Abud, Jairo. Net and total transition cost: the timing of economic reform. World Development, v. 25, n. 6, p. 905-914, 1997.

. Exchange rate: fix, float, or manage it? Prefácio a Mathias Vernengo (org.), Monetary integration and dollarization: no panacea. Cheltenham: Edward Elgar, 2004, p. xiii-xix.

Bresser-Pereira, Luiz Carlos; Nakano, Yoshiaki. Uma estratégia de desenvolvimento com estabilidade. Revista de Economia Política, v. 21, n. 3, p. 146-177, 2002.

Crescimento econômico com poupança externa? Revista de Economia Política, v. 22 , n. 2 , p. $3-27,2003$.

Bresser-Pereira, Luiz Carlos; Varela, Carmen A. The second Washington Consensus and Latin America's quasi-stagnation. Journal of Post Keynesian Economics, v. 27, n. 2, p. 231-250, 2004.

Bresser-Pereira, Luiz Carlos; Gala, Paulo. Crítica do crescimento com poupança externa. Texto para Discussão EESP/Fundação Getúlio Vargas 14\&, outubro 2005.

Bresser-Pereira, Luiz Carlos (ed.), Populismo econômico. São Paulo: Editora Nobel, 1991.

Canitrot, Adolfo. La experiencia populista de distribución de renta. Desarrollo Económico, v. 15 (59), p. 331-351, outubro de 1975.

Cline, William R. The United States as a debtor nation. Washington: Institute for International Economics, 2005.

Cline, William R.; Weintraub, Sidney (eds.), Economic stabilization in developing countries. Washington: The Brookings Institution, 1981. 
Davidson, Paul. Financial markets, money and the real world. Cheltenham: Edward Elgar Publishing, 2002.

Diaz-Alejandro, Carlos. Southern Cone stabilization plans. In: Cline, W.; Weintraub, S. (orgs.), op. cit., 1981, p. 119-148.

Dooley, Michael; Folkerts-Landau, David; Garber, Peter. An essay on the revived Breton Woods system. Cambridge, MA: NBER Working Paper 9971, September 2003.

. Interest rates, exchange rates and international adjustment. NBER Working Paper 11771, November 2005.

Economist, The. The disappearing dollar. The Economist, 2 de dezembro de 2004.

Eichengreen, Barry. Capital flows and crises. Cambridge: MIT Press, 2003.

Feldstein, Martin S. Distinguished lecture on economics in government: thinking about international economic coordination. Journal of Economic Perspectives, v. 2, n. 2, p. 3-14, 1988.

Frenkel, J. A.; Rockett, K. A. International macroeconomic policy coordination when policy-makers do not agree on the true model. The American Economic Review, 78, p. 318-340, 1988.

Galbraith, James K. Apocalypse not yet. Cópia: 06 de dezembro de 2004. Versão reduzida desse artigo em Newsday, 3 de dezembro de 2004.

Hausmann, Ricardo; Sturzenegger, Federico. 'Dark matter' makes the US deficit disappear. Financial Times, 8 de dezembro de 2005.

Jacquet, Pierre; Pisani-Ferry, Jean; Tubiana, Laurence (eds.), Gouvernance mondiale. Paris: La Documentation Française, 2002.

Jarret, Peter. Coping with the inevitable adjustment in the US current account. Economics Department Working Paper n.467, Dezembro 2005.

Kregel, Jan. Was there an alternative to the Brazilian crisis? Revista de Economia Politica, v. 19, n. 3, p. 23-38, 1999.

Kuroda, Haruhiko. The 'Nixon Shock' and the 'Plaza Agreement': lessons from two seemingly failed cases of Japan's exchange rate policy. China \& World Economy, v. 12, n. 1, p. 3-10, 2004.

Moggridge, D. Keynes. Londres: Macmillan, 1876.

Nonnenberg, Marcelo José Braga. Aumento do déficit em conta corrente norteamericano e perspectivas de desvalorização do dólar. nota técnica in Brasília: Boletim de Conjuntura (do IPEA), 68 março 2005, p. 82-84.

O’Donnell, Guillermo. State and alliances in Argentina, 1956-1976. In: O’Donnell, Guillermo (1999). Originalmente publicado em Desarollo Económico, janeiro de 1977.

. Counterpoints - Selected essays on authoritarianism and democratization. Notre Dame: Indiana University Press, 1999. 
Raffer, Kunibert; Singer, Hans W. The economic north-south divide. Cheltenham: Elgar Press, 2001.

Rajan, Ramkishen S.; Kiran, José; Hefeker, Carsten; Schnab, Gunther. The US dollar and the euro as international currencies. Intereconomics, v. 41, n. 6, p. 124-141, 2006.

Roseneau, James N. Turbulence in world politics: a theory of change and continuity. Princeton: Princeton University Press, 1990.

. Along the domestic-foreign frontier: exploring governance in a turbulent world. Cambridge: Cambridge University Press, 1997.

Sachs, Jeffrey D. Social conflict and populist policies in Latin America. In: Brunetta, R.; Dell-Arringa, C. (eds.), Labor relations and economic performance. London: Macmillan Press, 1989.

Stiglitz, Joseph E. Globalization and its discontents. Nova York: W.W. Norton, 2002.

UNCTAD. Trade and development report. Geneva: United Nations Conference on Trade and Development, 2001.

UNCTAD Secretariat. The financial crisis in East Asia: a background note. Genebra: janeiro de 1998.

Williamson, John. Curbing the boom-bust cycle: stabilizing capital flows to emerging markets. Washington: Institute for International Economics, 2005.

Wong, Wing-Keung; Khan, Habibullah. Can the American dollar survive the onslanght of the euro? An empirical investigation. Singapore: National University of Singapore e Universitas 21 Global, fevereiro de 2006. 